\title{
POESÍA EN
}

PERSPECTIVA: UN

RECONOCIMIENTO

Eduardo Milán*

\section{A fin de siglo, coincidente con el}

fin de milenio, es posible examinar algunas cuestiones relativas a la situación general de la poesía (léase, en cuanto a formulación teórica general, arte) y, a partir de ello, pensar acerca de sus alternativas.

I. La crisis de la modernidad afectó más de lo que se reconoce el arte de este siglo. Si bien el pensamiento postmoderno (independientemente de sus antecedentes, rastreables a través de toda la modernidad, especialmente luego del Iluminismo) emerge con claridad en la década de los setenta (según la puntual sintomatología reunida por Lyotard), es a través de acontecimientos históricos precisos (la caída del bloque socialista, la caída del muro de Berlín, etc.) donde ese pensamiento crítico de la modernidad logra traducirse en hechos concretos y palpables. En la crisis de ese pensamiento estalló, realmente, una secuela de no resoluciones de la modernidad que adquirieron fuerza a partir del siglo XVIII, clave para entender la vectorización del mundo a través de dos factores definitivos: la razón instrumental y la revolución industrial. La respuesta romántica a la condensación iluministra no descuidó, aún bajo amenaza, la profundización en la reflexión estética, una "ciencia" joven cuya edad no excedía el siglo anterior. Hegel, Lessing o los hermanos Schlegel hicieron suyas las contradicciones de un pensamiento sobre el arte que prometía, en caso de que el arte se

* Instituto Tecnológico Autónomo de México. 


\section{EDUARDO MILÁN}

confirmara como transitorio, es decir, que ya no vehiculizara las grandes necesidades del espíritu, ocupar el lugar de la obra misma (según la profesía hegeliana acerca del futuro del arte, cumplida a medias). $\mathrm{Si}$ el siglo XIX estéticamente se cierra con un poema nihilista, Un coup de dés n'abolirá l'azar (Mallarmé, 1987), no sorprende que Tristán Tzara, en 1918, proclame: "Dadá no significa nada". Sin embargo, el siglo no había abierto con un signo de continuidad estética: abrió con la puesta en escena de algo que expresa, en última instancia y para nosotros los humanos, el euforismo dionisíaco: la primera guerra mundial. La obertura es significativa de una manifestación clara al siglo $\mathrm{XX}$ : la interferencia de la historia en el continuum estético. Esto puede explicar tal vez la ambigüedad de un típíco movimiento de entreguerras como el surrealismo.

Contagiado por el móvil de la esperanza, que se necesita pero no se ve, el Manifiesto surrealista de André Breton apuesta todo o nada a la otra realidad, otredad que estuvo siempre en la mira de toda práctica artística. El desvelamiento de una obviedad puede ser triunfal en un momento de tiniebla histórica. No por eso, por su calidad de obvia luz, el surrealismo dejará de sufrir la siguiente paradoja: es un movimiento

120 estéticamente "reaccionario" por no profundizar la propuesta Dadá (continuación teórica de la idea hegeliana de "muerte del arte"); ejemplificando con la monarquía, si Dadá corresponde al momento revolucionario, el surrealismo corresponde a la Restauración. La debilidad del surrealismo no sólo se sitúa en el autoritarismo no-surrealista de su líder Breton ni tampoco en las componendas que debió realizar para mantenerse a flote. La debilidad surrealista reside, especialmente, en la fantasía de sus enunciados teóricos y en sus imposibilidades prácticas. A la "no practicidad" del surrealismo se enfoca la refutación de dicho movimiento desde las trincheras del mismo espíritu de las vanguardias históricas y de los movimientos neo-vanguardistas siguientes. La lógica de la vanguardia pedía, luego de Dadá, un renacer, no un restaurar: a las cenizas de Dadá correspondería un ave o una nueva forma de ave, nunca un monumento estetizante y de fundamentación canónica. En el siglo de la ruptura -éste que se acaba-el surrealismo 
POESÍA EN PERSPECTIVA

intentó reconectar el arte al sistema del mundo. La reconexión no era inocente: Breton esperaba que el mundo cambiara "para bien". El devenir histórico lo traicionó del mismo modo que Breton había traicionado a Tzara al introducir al surrealismo en la dinámica política militante.

II. En el ejemplo del movimiento surrealista se puede ver con claridad un signo de este -nuestro tiempo: la positivación de lo negativo. Con esta expresión quiero resaltar la reiterada actitud de la sociedad actual, la de cambiar de signo ciertas sintomatologías de la enfermedad social al no encontrarles remedio. Esta es una práctica que incluye varios niveles de lo social, desde la interpretación filosófica de la tradición a la distorsión de los hechos. Si un cierto pensamiento postmoderno puede, dado su carácter nihilista, reinterpretar el espíritu de la tragedia griega y positivizar a Edipo (el héroe de la violencia por definición, el catalizador discordante-dionisíaco), ello significa que la dimensión temporal histórica del pensamiento mítico -y su deriva trágica-ya no está en juego. Si Breton puede construir un monumento estético casi perfecto a partir del sacrificio de Dadá, todo indicaría que una dimensión del arte más allá del arte ya no está en juego y lo que sí está en juego es la dimensión estética aliada a una necesidad de seguimiento, de continuidad sin que los efectos del sacrificio se hayan cumplido.

III. Desde América Latina las cosas se ven, tal vez, de diferente manera. La "marginalidad favorable", un concepto que ha servido al arte latinoamericano para situarse con una posición de fuerza (la fuerza que otorga lo diferente) ante el arte europeo o neo-europeo (el norteamericano, claro está), posibilitó la creación en Brasil, a finales de la década de 1950, del movimiento de Poesía Concreta. Tres poetas brasileños, Augusto y Haroldo de Campos y Décio Pignatari, construyeron una teoría poética basada en una actitud muy cara a la marginalidad civilizatoria: la del "canibalismo cultural". Sobre la base de las visiones del escritor brasileño Oswald de Andrade, especialmente sobre las consideraciones de su Manifiesto Antropofágico (1928), los poetas brasileños imprimen sobre la cultura del mundo un ritual de devoración cultural. Esa "devoración" se practica en general a partir de una lectura desacralizadora y anticanónica de la tradición cultural occidental. La 
EDUARDO MILÁN

selección de sus modelos teóricos y prácticos (desde el siglo XIX en adelante: Hegel, Marx, McLuhan, Reinan Jakobson, James Joyce, Mallarmé, W.C. Williams, Ezra Pound, Maiacovsky, etc.) genera un paideuma (en palabras de Ezra Pound: "elenco de autores vigentes en un momento dado") que les permite la elaboración de uno de los más acabados modelos teóricos del arte creados en América Latina y, sin duda, la normalización más orgánica de un proyecto poético concebido en el Continente. Pero, especialmente, comparte una visión de la poesía que tuvo ecos internacionales muy precisos en aquellos escritores cuya participación en movimientos de vanguardia había marcado indeleblemente su quehacer (Stockhausen, Max Bill, Max Bense, Eugen Gomriger y otros). El poeta mexicano Octavio Paz reconoció la influencia de los poetas concretos brasileños durante la escritura de su poema Blanco (1967) y en su libro experimental Topoemas (1968), la postura teórica y práctica de los poetas de Sâo Paulo influyó profundamente en las nuevas generaciones de poetas conosureños (uruguayos y argentinos fundamentalmente). La temprana influencia en Octavio Paz (una influencia sobre todo práctica), no tuvo consecución inmediata en cuanto al efecto expansivo y más general de esta política del

122 rigor poético que representaron y representan los poetas mencionados. Hay que esperar al año de 1987 para que aparezca, en México, la traducción de una antología poética de Haroldo de Campos realizada por Manuel Ulacia y por mí, y publicada, con un prólogo mío que divulga la actitud poética de Haroldo de Campos, pero también del grupo, en ediciones El Tucán de Virginia.

IV. Me he detenido en manifestaciones de la vanguardia estética porque son las que presentan o manifiestan la preocupación por proyectos de escritura que son, también, la mayoría de las veces, formulaciones éticas o proposiciones de vida. Y porque, a mi juicio, está ahí, en la propuesta proyectiva o en su ausencia, en la mirada futurible o en su escamoteo, la razón, a mi juicio, de mucho del pesimismo imperante en la cultura actual, cuando no del libre "dejar pasar" del flujo nihilista decimonónico. Las vanguardias históricas no sólo precipitaron una crisis en el ámbito del arte, $\mathrm{Su}$ proyección alcanzó lo social con inusitada 
fuerza. La importancia modélica del impacto de las vanguardias es palpable cuando se advierte que todo un repertorio de formas artísticas "preparadas" para un cambio en el arte, que era, también, un cambio en la vida (es aleccionador aquí el papel trágico jugado por el futurismo y el constructivismo soviéticos) se quedó, históricamente, sin referentes. La crítica a los movimientos de vanguardia estéticos no proviene de acusaciones relativas al intento de prolongación en el tiempo de algo que se llama, justamente, vanguardia y que, por la misma lógica bélica de donde proviene la palabra, no puede durar mucho. La crítica no es, entonces, a la pretensión de la vanguardia de instalarse como un nuevo canon ("tradición de lo nuevo" según Harold Rosemberg; "tradición de la ruptura" según Octavio Paz): es una crítica a la falta de referentes a los que todo un repertorio formal aludía y ya no puede aludir. Lógicamente, si hay una dialéctica de la vanguardia, una pretensión utópica, al decretarse por un estado de cosas del mundo el "fin de la utopía" todo el repertorio formal que aludía a la posibilidad utópica se vuelve si no inoperante al menos sin lugar. Sin embargo, esa descolocación entre los repertorios formales epocales -lo que sustenta la posición de una historicidad de las formas, lo que posibilita creer en una transitoriedad formal-y los contenidos que vehiculizan ha sido una constante en la historia del arte vista en perspectiva. Ese "error" o traición de la forma al contenido ha posibilitado mucho del reciclaje formal de la historia del arte. En el campo de la poesía, por ejemplo, si fuera absolutamente justo el concepto de transitoriedad formal (coincidente aquí con la teoría evolutiva de las formas, cara al espíritu romántico y que ancló, también, en el positivismo) sería un absurdo la sola concepción o la posibilidad de que se escribieran sonetos a finales del siglo XX. Ocurre que, al tratarse un problema como el de la relación forma-contenido en un siglo como el nuestro, donde las promesas de cambio habían sido una proyección también del superyó cientificista de la época -la promesa de cambio estaba científicamente demostrada-, la constatación del no isomorfismo arte-vida, la no ligazón forma-contenido parece un fracaso del arte mismo y la caducidad de todas las formas pensadas o imaginadas a-raíz de una posibilidad. 


\section{EDUARDO MILÁN}

La forma fragmento es un buen ejemplo de lo que digo. Si la escritura fragmentaria tuvo tanto éxito en la primera mitad del siglo XX -lo que permitiría ver en ese lapso un corno de "los años del fragmento"podría decirse que el fragmento era la forma idónea de un mundo que se mostraba en apariencias a todas luces fragmentado: desde la física y la constatación relativista de que el universo no presentaba leyes estables como para una conclusión definitiva hasta el movimiento de la sociedad que se debatió, en los primeros cincuenta años del siglo, entre la promesa de un cambio y la guerra. El fragmento no parece ser tanto un resto de forma, una ruina formal proveniente de un quiebre de carácter epistemológico o de una toma de conciencia de la fragilidad del proyecto moderno o de la violencia de la razón instrumental. El fragmento parece corresponder, en los primeros cincuenta años, a una imagen del mundo. Así, con la lógica que vincula directamente al escritor y su tiempo, se puede decir que ni el Finnegans wake de James Joyce ni The waste land de T.S. Eliot ni Trilce de Cesar Vallejo ni En la masmédula de Oliverio Girondo -todos textos de extrema fragmentación- podrían haber sido escritos en ningún otro momento histórico que entre 1900 y 1950 . Pero hay algo que delata la fortuna de la forma

124 fragmentaria en nuestro siglo. Se trata de la crisis de la idea de arte como ilusión. La célebre frase de Picasso, "el arte es una mentira que dice la verdad", demanda algo muy similar a lo demandado por John Keats el siglo anterior: "Beauty is truth, truth beauty... dice el romántico inglés al concluir su Ode on a grecian urn (1819). Existe la sospecha, detrás de la poética del fragmento, de que en esta forma hay algo que no hay, como si la conciencia estética fuera clara en cuanto sabe que se trata de una sobrevivencia, de un arte que sobrevivió, con toda la lógica entre culposa, irresponsable y fundamentalista que el haber sobrevivido conlleva. En la forma fragmento se presenta como ausencia la estética de la "muerte del arte", siempre sacrificial y renaciente, de Hegel en alianza con la forma de la imagen del mundo. Lo que no hay, y el fragmento sabe que no hay, es significación en la más amplia noción de sentido. Con esa conciencia el arte ya deja de ser el ejercicio de "gozar de los sentidos" para transformarse en la demanda de otra 


\section{POESÍA EN PERSPECTIVA}

cosa. Esa verdad que entre líneas demanda el gran arte de nuestro siglo ya no puede ser la belleza o ya no la misma belleza que era certeza para Keats. Esa belleza fue cuestionada en el siglo XIX por Rimbaud ("senté a la belleza en mis rodillas y la encontré horrible") y, de una manera más cultural y menos individual, por Dadá en nuestro siglo. La demanda no es, entonces, por la falta estética o por el "principio del placer" que otorgó, alguna vez, el arte. Se trata de una belleza que, secularmente, vivifique la necesidad del artista y del poeta de estar en un terreno estable y con carácter absoluto, de algo como una religión que vuelva a significar o re-vincular el diálogo Divinidad-poeta en cuya ruptura Hölderlin cifró la tragedia de su (nuestra) época. Esa belleza no puede estar en ningún otro lugar más que vinculada a lo que todavía no hay, en términos de Ernst Bloch, no sólo como vínculo sino, mejor, como la condición anticipatoria de ese no-todavía-latente. La autonomía del arte, conquista decimonónica relativa a la no dependencia del arte de la sociedad y luego de la realidad (vencía así una larga lucha por la independencia de la idea de mímesis), se pagó cara en este siglo XX cuando la vanguardia decretó a ese mismo arte autónomo obsoleto. Si, por un lado, como el mismo Bloch señala, el arte (o la belleza) es utópico en sí mismo, utópico ante su misma belleza anticipada, viene (iba necesariamente a venir) al caso la pregunta: ¿en qué mundo se da ese arte? La carrera a velocidad refleja fue perdida por el poeta. Al mundo no le importó la "conciencia desdichada" del poeta porque había una conciencia un poco más general que la del poeta que había entrado en crisis apenas iniciado el siglo. La conciencia de la guerra pareció más importante que la "conciencia desdichada", aún la conciencia de la guerra como locura o estupidez que hizo decir a Joyce: "El Ulises es más importante que la Segunda Guerra Mundial". Las vanguardias estéticas consideradas como un fenómeno de postguerra corrieron el riesgo de transformarse en un fenómeno de entredos-guerras. Todo lo cual, en un mundo de frases célebres como el actual, nos lleva a la tristemente célebre frase de Adorno: "Es imposible escribir poesía después de Auschwitz." Pero lo que verdaderamente parece imposible, a la hora de los funerales del arte, es olvidar que 


\section{EDUARDO MILÁN}

nuestro siglo ha sido signado por la guerra desde su comienzo. Y no sólo por la primera o por la segunda guerras mundiales sino por toda la guerra: por la amenaza de la guerra y por el peligro de la guerra, sin contar las más de trescientas guerras locales o particulares que llevamos hasta ahora. Ante un paisaje semejante es difícil plantear un seguimiento serio o un devenir de la estética decimonónica en el siglo $\mathrm{XX}$. La autonomía del arte o la aniquilación del arte son conceptos inútiles cuando la lógica del mundo escapa del dominio estético, cuando el artista, por una resolución ética, se ve obligado a dar testimonio del mundo, o cuando el arte se integra dentro de una lógica más amplia de resistencia humana. Aquí, en este último caso, el seguir haciendo arte se plantea corno una memoria ciega, sabia, que tiene que ver una vez más con la esperanza y no tanto con la evidencia.

V. No parece haber, entonces, salidas o soluciones lógicas para la encrucijada del arte actual y, dentro del arte, para la encrucijada en la que también se encuentra la poesía. Habría que resolver con una cierta urgencia la cuestión de si el problema de la poesía es un problema de su íntima competencia o si es un problema del mundo. La sociología es cauta cuando toca estos problemas. Generalmente remite la parti-

126 cularidad de un tiempo histórico a la generalidad difícil de todos los tiempos. La filosofía, sobre todo la filosofía que se detiene ante la necesidad de superación del nihilismo otorgó, por boca de Heidegger, la palabra a los poetas. Y, en efecto, sí parece haber una ligazón consciente o inconsciente entre la visión presocrática de los poetas como vates o vaticinadores y la concepción de belleza como anticipación de Ernst Bloch. Entre el maníaco que delira poseído por una visión y el que ve la esperanza como condición de sobrevivencia en la materia, no parece haber mucho trecho. Varios puntos caros a una básica noción humana se tocan en esa forma de fe en la poesía (Heidegger) o en la belleza (Bloch). 1) La fe en que la poesía es una forma de captación del futuro o, con seguridad, del aire de los tiempos. Ezra Pound decía que los poetas eran las antenas de la especie. Esta concepción se liga con la noción del poeta como visionario, una noción muy cara al romanticismo decimonónico pero también, y por deriva romántica, a la 
antigüedad griega. 2) La fe en que la poesía es generada por la subjetividad humana. Entra en cuestionamiento así el estatuto de veracidad objetiva y con él toda la razón instrumental puesta en marcha en forma consciente desde el Iluminismo, con furor pragmático durante la revolución industrial y, con acentuada positivación, en esta fase postmediática de la tercera revolución tecnológica. Viene al caso recordar la exitosa frase del célebre físico: "Ya que Dios me hizo sujeto soy subjetivo. Si me hubiera hecho objeto sería objetivo." 3) La fe en que la poesía es la más inútil de las artes que sobreviven, es decir, que "no sirve para nada". En un mundo instrumentalizado como el nuestro, que haya una práctica específica que no sirva para nada tiene varias connotaciones: a) existe la posibilidad, aun en este mundo, de una práctica legendaria como la historia misma de no subordinación a ningún orden institucionalizado; b) que ya que no sirve para nada, que es completamente inútil, puede vehiculizar formas subjetivas no codificables y por lo tanto no reductibles a la calidad de información y, aún más, de comunicación. Esta concepción remite tanto a la posición "en huelga" de Mallarmé a finales del siglo pasado, como a la noción del poema como erizo de Jacques Derrida. 4) La fe en que la poesía constituye, como palabra articulada de una manera específica, una forma de memoria y que, como forma de memoria puede contaminar otras formas de memoria de cara a la necesidad de sobrevivencia de la tradición, por ejemplo, en un mundo que amenaza con convertir a la idea de tradición en fragmentos discontinuos de presente. 5) La fe en que la poesía puede, por su alianza con la memoria, superar el impasse que ha significado primero el proyecto moderno y, luego, las sucesivas derivaciones postmodernas, neomodernas o finalistas. No hay tanta certidumbre de que las artes plásticas puedan seguir manteniendo lo que todavía queda de estatuto estético no mercantilizable. Esta condición de "insobornable" de la poesía ante el mercado, ante toda una forma de poder, la vuelve el comodín de las artes humanísticas. Como matiz de esta certidumbre hay que plantear nuevamente la pregunta por la relación de la poesía con las nuevas maneras de normalización tecnológica. 


\section{EDUARDO MILÁN}

VI. Lo que sí parece un hecho irrefutable en el momento actual es que se ha creado una nueva relación, por no decir interdependencia, entre arte, poesía y mundo. Cuando el suelo mismo del planeta está siendo afectado no parece pertinente, más que en un nivel meramente académico, plantearse problemas como el de la autonomía del arte, o no de la misma manera en que fue planteado hace un siglo. Todos los quehaceres de carácter humanístico parecen involucrados en librar la batalla por la sobrevivencia, tanto en un nivel elemental, ecológico, como en niveles menos elementales como el ético, el económico y el estético. El papel o la función de la poesía, más allá de ser poesía, parecería estar ligado como otro a quehacer a ese mismo sentido de esperanza. 